Communications in Physics, Vol.21, No. 1 (2011), pp. 43-49

\title{
EFFECT OF HEATING RATE ON THE RESPONSES OF LiF: Mg, Cu, Na, Si THERMOLUMINESCENT PHOSPHOR
}

\author{
VU THI THAI HA AND NGUYEN THI QUY HAI \\ Institute of Materials Science, VAST \\ NGUYEN NGOC LONG \\ Center for Materials Science, Hanoi University of Science, VNU
}

\begin{abstract}
In the current work the glow curves for LiF:Mg, Cu,Na, Si thermoluminescent material were measured and analyzed by using a function approximating to the well-known Randall-Wilkins first-order expression. The influence of different heating rates on thermoluminescent glow-peak maximum temperature, peak height and integrated area of the glow peak was investigated for LiF:Mg,Cu,Na,Si phosphor. The results show that the glow-peak temperature, peak height and glow peak area increase with increasing heating rate, while the full width at half maximum of glow peak almost keeps constant in the range of heating rates studied.
\end{abstract}

\section{INTRODUCTION}

Thermoluminescence (TL) is the thermally stimulated emission of light of an insulator or semiconductor which has been exposed to ionizing radiation. During irradiation, electrons and holes are created and some of them are trapped at defect sites. The trapped charge carriers can be liberated by heating the sample and will move to lower energy state with emission of light. The study of the TL glow curve, which is a plot of TL light versus temperature, is used to determine the trapping parameters. However, the TL response strongly depends on heating rate, an important parameter in the TL measurements. Influence of the heating rate on TL glow curve has been the object of study by different authors $[1-10]$.

In 1989, Kim et al. developed a powder-type of LiF doped with four dopants: $\mathrm{Mg}$, $\mathrm{Cu}, \mathrm{Na}$ and $\mathrm{Si}[11,12]$. These TL powders have about 2 and 75 times higher sensitivity in comparison with $\mathrm{LiF}: \mathrm{Mg}, \mathrm{Cu}, \mathrm{P}$ [13] and $\mathrm{LiF}: \mathrm{Mg}, \mathrm{Ti}$ (TLD-100) [14], respectively. The $\mathrm{LiF}: \mathrm{Mg}, \mathrm{Cu}, \mathrm{Na}$,Si material with linear TL response over a wide dose range, low residual signal, and good stability to heat treatment is found to be a promising material for thermoluminescent dosimetry. In the last ten years, the $\mathrm{LiF}: \mathrm{Mg}, \mathrm{Cu}, \mathrm{Na}, \mathrm{Si}$ material has attracted the researchers' attention. The effect of the dopant concentrations on the TL glow curve in LiF:Mg, Cu,Na,Si phosphor was investigated $[15,16]$. The role of the dopants

in TL mechanism for $\mathrm{LiF}: \mathrm{Mg}, \mathrm{Cu}, \mathrm{Na}$, Si phosphor was studied by analysing the TL emission spectra [17-19]. However, to the best of our knowledge, up to now, there is almost no work about the evaluation of the trapping parameters and the influence of the heating rate on TL response for $\mathrm{LiF}: \mathrm{Mg}, \mathrm{Cu}, \mathrm{Na}, \mathrm{Si}$ phosphor. 
The aim of the present work is to analyse the TL glow curve of $\mathrm{LiF}: \mathrm{Mg}, \mathrm{Cu}, \mathrm{Na}, \mathrm{Si}$ phosphor into its component peak using a function approximating to the well-known Randall-Wilkins first-order expression of a single glow peak and to study the influence of the heating rate on TL response for $\mathrm{LiF}: \mathrm{Mg}, \mathrm{Cu}, \mathrm{Na}, \mathrm{Si}$ phosphor.

\section{EXPERIMENTAL}

\section{II.1. Phosphor preparation}

Host LiF material was prepared by means of the reaction:

$$
\mathrm{LiCl}+\mathrm{HF} \rightarrow \mathrm{LiF}+\mathrm{HCl}
$$

The precipitated LiF was filtered, washed repeatedly and dried. Synthesis process for $\mathrm{LiF}: \mathrm{Mg}, \mathrm{Cu}, \mathrm{Na}, \mathrm{Si}$ TL powders described elsewhere [20] is as follows: The host $\mathrm{LiF}$ material was mixed with the compounds containing required activators $\mathrm{MgCl}_{2} \cdot 6 \mathrm{H}_{2} \mathrm{O}$, $\mathrm{CuCl}_{2} \cdot \mathrm{H}_{2} \mathrm{O}$ and $\mathrm{Na}_{2} \mathrm{SiO}_{3} \cdot 9 \mathrm{H}_{2} \mathrm{O}$ in distilled water. The mixture was mixed on a magnetic stirrer and was then dried in an oven at $150{ }^{\circ} \mathrm{C}$ for 15 hours. The dried material was kept in a platinum crucible and sintered in a muffle furnace at $800{ }^{\circ} \mathrm{C}$ for $30 \mathrm{~min}$ in a controlled nitrogen atmosphere. Then the furnace was quickly cooled to room temperature. Final product was pulverized, sieved to select grains having sizes in the range of $60-150 \mu \mathrm{m}$. The color of the pulverized phosphor was bluish. It seems that the $\mathrm{Cu}$ dopant diffused not completely into $\mathrm{LiF}$, therefore the excess $\mathrm{Cu}$ dopant compound agglutinated to the surface of the $\mathrm{LiF}$ crystallites. In order to remove the excess $\mathrm{Cu}$ impurities, the powders were firstly rinsed with $\mathrm{HCl}$ solution, then washed with water and finally dried. After acid treatment, the LiF:Mg, Cu,Na,Si phosphor turned white.

The $\mathrm{LiF}: \mathrm{Mg}, \mathrm{Cu}, \mathrm{Na}$,Si powders were prepared with dopant concentrations varied in the same ranges as [15]: $\mathrm{Mg}$ 0.2-1.0 mol\%, Cu 0.2-1.0 mol\%, NaSi 1.6-2.4 mol\% (NaSi was considered as a single dopant and its concentration was calculated as total of $\mathrm{Na}$ and $\mathrm{Si}$, because the compound $\mathrm{Na}_{2} \mathrm{SiO}_{3} \cdot 9 \mathrm{H}_{2} \mathrm{O}$ was added). Based on our analysis of the dependence of the intensity for the TL glow curves on the dopant concentration [21], it was found that the optimum dopant concentrations were $0.2 \mathrm{~mol} \% \mathrm{Mg}, 0.6 \mathrm{~mol} \% \mathrm{Cu}$ and $2.0 \mathrm{~mol} \% \mathrm{NaSi}$. So, this sample was used for the experiments in the current work.

\section{II.2. Thermoluminescence measurements}

The $\mathrm{LiF}: \mathrm{Mg}, \mathrm{Cu}, \mathrm{Na}$,Si powders were irradiated by X-ray radiation. All the samples were irradiated to the same dose of 0.1 Gy from an X-ray tube (RORIX, RFT, Germany) $1.5 \mathrm{~kW}$ in power with a cobalt target, operated at $20 \mathrm{kV}$ and $1-5 \mathrm{~mA}$. X ray irradiation procedure was carried out for a large mass $(300 \mathrm{mg})$ of the phosphor powder. This phosphor powder mass was filled in a tray of $15 \mathrm{~mm}$ in diameter; the tray was placed in the middle of the X ray beam with the size of $30 \mathrm{~mm}$. After every $30 \mathrm{~s}$ of irradiation, the tray was taken out and the powder was steady stirred for $10 \mathrm{~s}$, and then the powder tray was irradiated again. The total irradiation duration was 3 minutes. For each TL measurement, $5 \mathrm{mg}$ of powder was taken out at random from the above irradiated $300 \mathrm{mg}$ of powder.

The TL glow curves of the samples were subsequently measured by using a commercial TLD reader (Harshaw TLD-3500) controlled by a computer. The error in temperature 
when using Harshaw TLD-3500 is $1 \mathrm{~K}$. In the TL readout, the $5 \mathrm{mg}$ of the phosphor powders were filled in a hole of $3 \mathrm{~mm}$ in diameter on a copper plate. The powder layer had a thickness below $1 \mathrm{~mm}$. The TL glow curve measurements were carried out 24 hours after irradiation with linear heating rates from $1 \mathrm{~K} / \mathrm{s}$ up to $30 \mathrm{~K} / \mathrm{s}$ in temperature range from $323 \mathrm{~K}$ to $633 \mathrm{~K}$. The TL measurements at a given heating rate were repeated 5 times and the results are represented by the average values with the mean deviation. The measurement data were processed using the software ORIGIN.

\section{RESULTS AND DISCUSSION}

\section{III.1. Deconvolution of glow curve}

The application of the glow-curve deconvolution technique for the analysis of a composite TL glow curve into its individual glow peaks has become very popular during the last two decades. Many functions describing a single glow peak were proposed, which were summarized and analyzed in details by Bos et al. [22-24]. Kitis et al. [25] proposed approximative functions for the Radall-Wilkins [26] first-order expression of a single glow peak under condition of linear heating. In addition, Kitis et al. [25] showed that their approximative functions yield accurate values of the activative energy within $3 \%$ of the correct values.

In the present work the glow curves of the $\mathrm{LiF}$ powders doped with $0.2 \mathrm{~mol} \% \mathrm{Mg}, 0.6$ mol\% $\mathrm{Cu}$ and $2.0 \mathrm{~mol} \% \mathrm{NaSi}$ were measured with different heating rates. A typical glow curve measured at the heating rate of $1 \mathrm{~K} / \mathrm{s}$ is shown in figure $1(\mathrm{a})$. In this measurement we used a contact heating technique with linear heating. Studying the temperature profile of the sample in the case of contact heating with constant heating rate, the authors of the works [27-29] have found that after a transitional period the temperature profile of the sample has the same form as that of the heating element but with an effective heating rate smaller than that of heating element.

Therefore, in this work the experimental glow curve has been analysed into its component glow peaks, each described by the first-order kinetics function of Kitis et al. [25]:

$$
I(T)=I_{m} \exp \left\{1+\frac{E}{k T} \frac{T-T_{m}}{T_{m}}-\frac{T^{2}}{T_{m}^{2}} \exp \left[\left(\frac{E}{k T} \frac{T-T_{m}}{T_{m}}\right)\left(1-\frac{2 k T}{E}\right)\right]-\frac{2 k T_{m}}{E}\right\}
$$

where $I_{m}$ and $T_{m}$ are, respectively, the intensity and the temperature at the maximum, $E$ is the activation energy, $k$ is Boltzmann constant. The analysis of the glow curve was carried out using an ORIGIN sorfware. As seen from figure 1(a), the fitted curve using a superposition of single peaks is in good agreement with the measured glow curve. The goodness of the fit has been tested with the figure of merit (FOM) defined by Balian et al. [30]:

$$
F O M=\sum_{i=1}^{n} \frac{\left|\Delta y_{i}\right|}{A}
$$

where is the number of data points, is the absolute value of the difference between the experimental and theoretical value and is the integral of the fitted glow curve. In the case 
of the glow curve for $\mathrm{LiF}: \mathrm{Mg}, \mathrm{Cu}, \mathrm{Na}, \mathrm{Si}$ shown in figure $1(\mathrm{a}), \mathrm{FOM}=0.0001 \%$. It was found that the main-peak maximum temperature of experimental data almost coincided with that of fitted glow curve. This is because the other component glow peaks are much weaker than the main glow peak; therefore they have a negligible influence on the mainpeak maximum temperature.
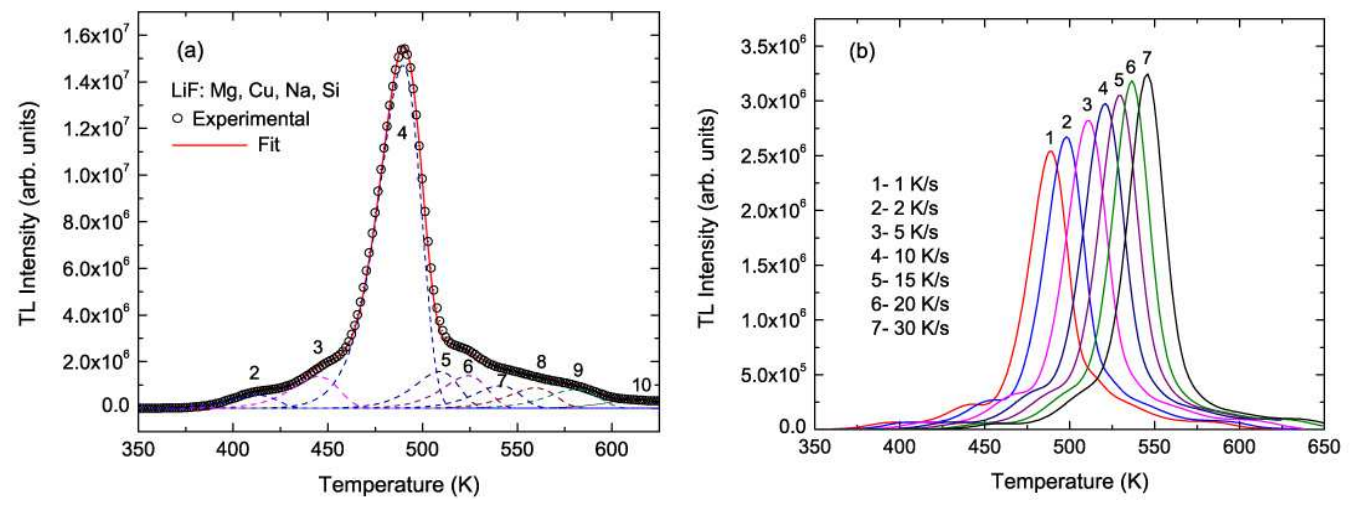

Fig. 1. (a) Glow curve of the $\mathrm{LiF}$ powders doped with $0.2 \mathrm{~mol} \% \mathrm{Mg}, 0.6 \mathrm{~mol} \%$ $\mathrm{Cu}$ and $2.0 \mathrm{~mol} \% \mathrm{NaSi}$ measured at the heating rate of $1 \mathrm{~K} / \mathrm{s}$, (b) Glow curves of the $\mathrm{LiF}: \mathrm{Mg}, \mathrm{Cu}, \mathrm{Na}, \mathrm{Si}$ powders measured at different heating rates.

For the main glow peak (at about $490 \mathrm{~K}$ ), the values of the fitting parameters were $E=1.89 \mathrm{eV}, T_{m}=489.5 \mathrm{~K}, I_{m}=15.4 \times 10^{6}$ (arb. units). The frequency factor $s=$ $2.59 \times 10^{18} \mathrm{~s}^{-1}$ was evaluated from the following expression

$$
s=\frac{\beta E}{k T_{m}^{2}} \exp \left(\frac{E}{k T_{m}}\right)
$$

where $\beta$ is the heating rate.

\section{III.2. Effect of heating rate on TL glow-peaks}

The heating rate is a fundamental experimental variable in TL measurements. Influence of heating rate on TL glow curve for various phosphors is rather complicated. Kitis et al. [1] studied the influence of heating rate on the TL response for LiF (TLD-700). They found that as the heating rate increases, the maximum temperature $T_{m}$ of the glow peak shifts to higher temperatures, the full width at half maximum (FWHM) increases and the area of glow-peak (integral TL) decreases.

Abtahi et al. [4] revealed that even for heating rates as high as nearly $10^{4} \mathrm{~K} / \mathrm{s}$ achieved by using uniform laser beam heating, no significant thermal quenching effect exists in LiF (TLD-100) for the dosimetric glow peaks. An increase of the integral TL with increasing heating rate has been observed in $\mathrm{LiF}: \mathrm{Mg}, \mathrm{Ti}[5-7]$. Pradhan [3] reported that the glow-peak areas of $\mathrm{LiF}$ TLD-700 ribbons and $\mathrm{LiF}: \mathrm{Mg}, \mathrm{Cu}, \mathrm{P}$ increase for the heating rates in the range from $1 \mathrm{~K} / \mathrm{s}$ to $20 \mathrm{~K} / \mathrm{s}$. Meanwhile Luo et al. [9] reported that peaks $3+4$ in $\mathrm{LiF}: \mathrm{Mg}, \mathrm{Cu}, \mathrm{P}$ remain almost unchanged at $90 \%$ of the total integral. Recently 
Pradhan et al. [10] reported that in $\mathrm{LiF}: \mathrm{Mg}, \mathrm{Cu}, \mathrm{Si}$ the main glow peak did not exhibit any significant reduction with increasing heating rate in the range from 1 to $30 \mathrm{~K} / \mathrm{s}$.
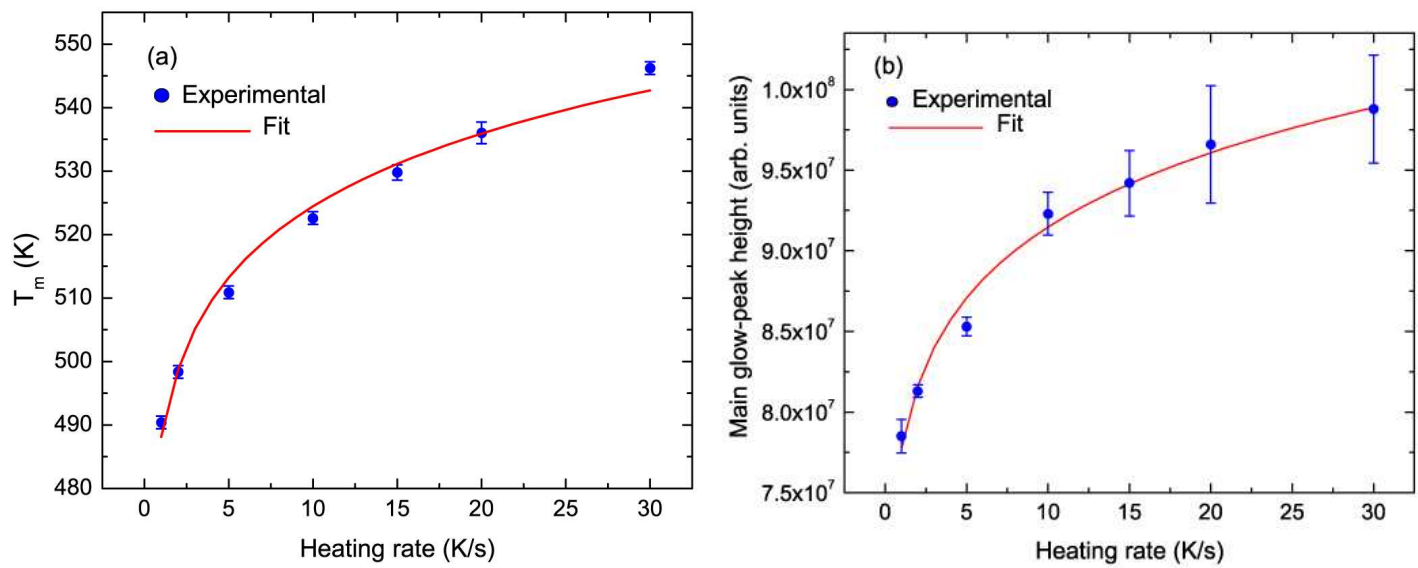

Fig. 2. (a) The main glow-peak maximum temperature as a function of heating rate for $\mathrm{LiF}: \mathrm{Mg}, \mathrm{Cu}, \mathrm{Na}$,Si phosphor, (b) Plot of the height of the main glow peak against heating rate.

In the present work, TL glow curves were measured with heating rates in the range from $1 \mathrm{~K} / \mathrm{s}$ to $30 \mathrm{~K} / \mathrm{s}$. Figure 1(b) shows typical glow curves of $\mathrm{LiF}: \mathrm{Mg}, \mathrm{Cu}, \mathrm{Na}$,Si powder measured at some heating rates. As seen from the figure, the whole TL glow curve is shifted to higher temperatures and the height of the main glow peak increases with increasing heating rate in the range from $1 \mathrm{~K} / \mathrm{s}$ to $30 \mathrm{~K} / \mathrm{s}$. We focused only on the main glow peak because it usually used in the dosimetric measurements. Figure 2(a) shows the plot of the main glow-peak maximum temperature $\left(T_{m}\right)$ against heating rate. Figure $2(\mathrm{~b})$ shows the plot of the height of the main glow peak $\left(I_{m}\right)$ as a function of heating rate.

Like as [1], we suppose that the change of the $T_{m}$ and $I_{m}$ against heating rate follows an equation of the form $\ln \left(T_{m}\right.$ or $\left.I_{m}\right)=A+B \ln (\beta)$, where $A$ and $B$ are constants and $\beta$ is the heating rate. For the glow-peak maximum temperature $A=6.1906 \pm 0.0034 ; B=$ $0.0312 \pm 0.0015$ and for the height of the main glow-peak $I_{m}, A=18.1683 \pm 0.0085 ; B=$ $0.0709 \pm 0.0038$. Using these constants, we calculated the dependence of $T_{m}$ and $I_{m}$ on $\beta$. The results are shown by the solid lines in figures $2(\mathrm{a})$ and $2(\mathrm{~b})$. It can be noted that the fitted lines are in rather good agreement with experimental data.

In our experiment, it was revealed that the integral TL, firstly, rapidly increases with increasing heating rate in the range from $1 \mathrm{~K} / \mathrm{s}$ to $10 \mathrm{~K} / \mathrm{s}$, then it keeps almost constant for increasing heating rate up to $30 \mathrm{~K} / \mathrm{s}$ (see figure $3(\mathrm{a})$ ), but the FWHM of the main glow-peak almost keeps constant in the whole heating rate range from $1 \mathrm{~K} / \mathrm{s}$ to 30 $\mathrm{K} / \mathrm{s}$ (see figure $3(\mathrm{~b})$ ). In the figure $3(\mathrm{a})$ the results obtained for $\mathrm{LiF}: \mathrm{Mg}, \mathrm{Cu}, \mathrm{Si}$ [10] are shown for comparison. The increase of the integral TL with increasing heating rate can be explained by the defect interaction model during TL read-out suggested by Piters and Bos [31]. 

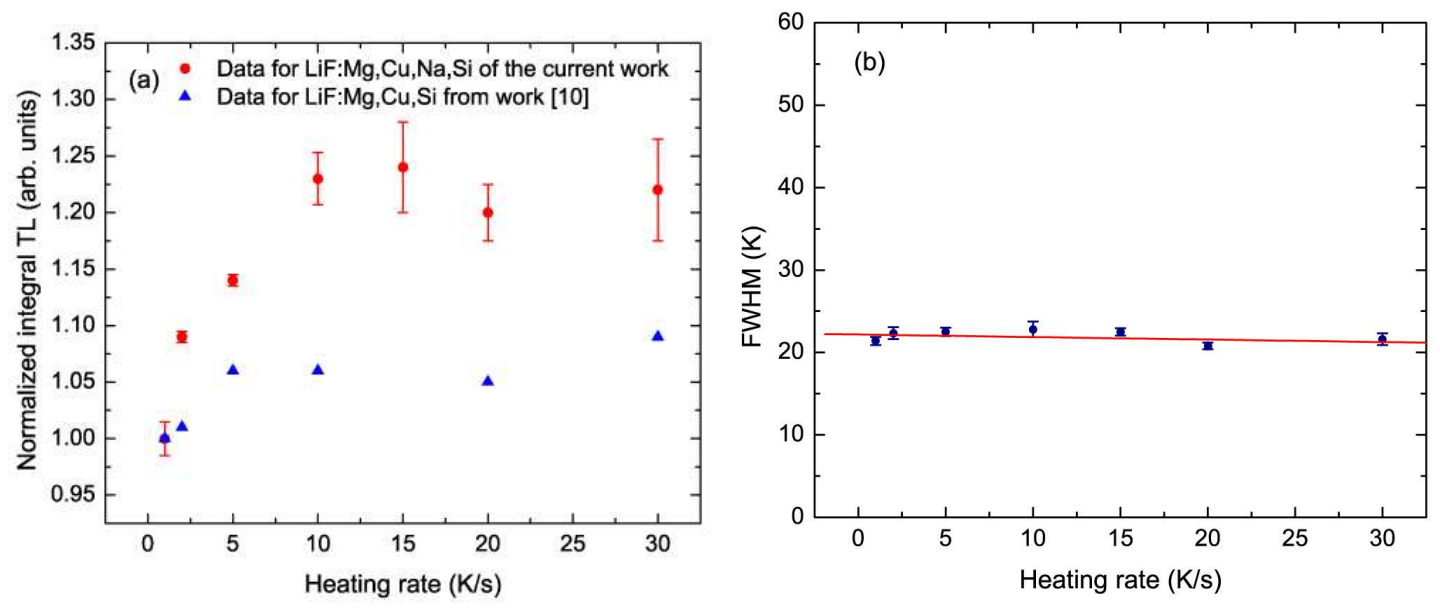

Fig. 3. (a) Integral TL normalized to that obtained with the heating rate of $1 \mathrm{~K} / \mathrm{s}$ as a function of heating rate for LiF:Mg, Cu,Na,Si phosphor, (b) Plot of FWHM of the main glow-peak against heating rate for $\mathrm{LiF}: \mathrm{Mg}, \mathrm{Cu}, \mathrm{Na}, \mathrm{Si}$ phosphor.

\section{CONCLUSION}

The experimental TL glow curve for $\mathrm{LiF}: \mathrm{Mg}, \mathrm{Cu}, \mathrm{Na}, \mathrm{Si}$ phosphor was analyzed into its individual glow peaks by using the first-order kinetic equation. The influence of the heating rate in the range from $1 \mathrm{~K} / \mathrm{s}$ to $30 \mathrm{~K} / \mathrm{s}$ on the TL response was investigated. It was found that the glow-peak maximum temperature and the peak height increased in the whole range of heating rates studied, while the integral TL increased with increasing heating rate from $1 \mathrm{~K} / \mathrm{s}$ to $10 \mathrm{~K} / \mathrm{s}$, and afterward kept almost constant for increasing heating rate up to $30 \mathrm{~K} / \mathrm{s}$. In particular, the full width at half maximum of glow peak kept constant in the whole range of heating rates studied. For the main glow peak (at about $490 \mathrm{~K}$ ), the kinetic parameters of the traps such as the activation energy and the frequency factor were evaluated to be $E=1.89 \mathrm{eV}$ and $s=2.59 \times 10^{18} \mathrm{~s}^{-1}$, respectively.

\section{REFERENCES}

[1] G. Kitis , M. Spiropulu , J. Papadopoulos, S. Charalambous, Nucl. Instrum. Methods Phys. Res., B73 (1993) 367.

[2] N.A. Sooner, A.D. Franklin, Radiation Measurements, 35 (2002) 59.

[3] A.S. Pradhan, Radiat. Prot. Dosim., 58 (1995) 205.

[4] A. Abtahi, P. Braunlich, T. Haugan, P. Kelly, Radiat. Prot. Dosim., 17 (1986) 313.

[5] G.C. Taylor, E. Lilley, J. Phys. D: Appl. Phys., 15 (1982) 2053.

[6] A.J.J. Bos, R.N.M. Vijverberg, T.M. Piters, S.W.S. McKeever, J. Phys. D: Appl. Phys., 25 (1992) 1249 .

[7] A.J.J. Bos, T.M. Piters, Radiat. Prot. Dosim., 47 (1993) 41.

[8] F.O. Ogundare, F.A. Balogun, L.A. Hussain, Radiation Measurements, 40 (2005) 60.

[9] L.Z. Luo, K.J. Velbeck, M. Moscovitch, J.E. Rotunda, Radiat. Prot. Dosim., 119 (2006) 184.

[10] A.S. Pradhan, J.I. Lee, J.L. Kim, K.S. Chung, H.S. Choe, K.S. Lim, Radiation Measurements, 43 (2008) 361. 
[11] S.H. Doh, M.C. Chu, W.H. Chung, H.J. Kim, D.S. Kim, Y.H. Kang, Korean Appl. Phys., 2 (1989) 425.

[12] H.J. Kim, W.H. Chung, S.H. Doh, M.C. Chu, D.S. Kim, Y.H. Kang, J. Korean Phys. Soc., 22 (1989) 415.

[13] Y.M. Nam, D.W. Lee, W.H. Chung, S.H. Doh, G.D. Kim, H.J. Kim, Korean Appl. Phys., 11 (1998) 102.

[14] S. Miljanic, M. Ranogajec-Komor, Z. Knezevic, M. Stuhec, M. Prokic, Radiat. Prot. Dosim., 119 (2006) 191.

[15] Y.M. Nam, J.L. Kim, S.Y. Chang, Radiat. Prot. Dosim., 84 (1999) 231.

[16] J.L. Kim, J.I. Lee, S.Y. Chang, K.S. Chung, H.S. Choe, Radiation Measurements, 38 (2004) 435.

[17] J.I. Lee, J.L. Kim, S.Y. Chang, Radiat. Prot. Dosim., 115 (2005) 340.

[18] J.I. Lee, D. Lee, J.L. Kim, S.Y. Chang, K.S. Chung, H.S. Choe, Radiat. Prot. Dosim., 119 (2006) 340.

[19] B. Yang, Q. Lu, S. Wang, P.D. Townsend, Nucl. Instr. and Meth. Phys. Res., B239 (2005) 171.

[20] Vu Thi Thai Ha, Nguyen Thi Quy Hai, Nguyen Ngoc Long, Le Van Vu, Vietnam National University Journal of Science, Mathematics - Physics, 23 (2007) 225.

[21] Vu Thi Thai Ha, Nguyen Thi Quy Hai, Nguyen Ngoc Long, Vietnam National University Journal of Science, Mathematics - Physics, 25 (2009) 83.

[22] A.J.J. Bos, T.M. Piters, J.M. Gomez Ros, A. Delgado, Radiat. Prot. Dosim., 47 (1993) 473.

[23] A.J.J. Bos, T.M. Piters, J.M. Gomez Ros, A. Delgado, Radiat. Prot. Dosim., 51 (1994) 257.

[24] A.J.J. Bos, Radiation Measurements 41 (2007) S45.

[25] G. Kitis, J.M. Gomez Ros, J.W.N. Tuyn, J. Phys. D: Appl. Phys., 31 (1998) 2636.

[26] J.T. Randall, M.H.F. Wilkins, Proc. R. Soc. London A, 184 (1945) 366.

[27] D.S. Betts, P.D. Townsend, J. Phys. D: Appl. Phys., 26 (1993) 849.

[28] T.M. Piters, A.J.J. Bos, J. Phys. D: Appl. Phys., 27 (1994) 1747.

[29] V.I. Gotlib, Ch L.N.Kantorovi, V.L. Grebenshicov, E.A. Nemiro, J. Phys. D: Appl. Phys., 17 (1984) 2097.

[30] H.G. Balian, N.W. Eddy, Nucl. Instrum. Methods, 145 (1977) 389.

[31] T.M. Piters, A.J.J. Bos, J. Phys. D: Appl. Phys., 26 (1993) 2255.

Received 23 August 2010. 